\title{
Analysis of the causes of defects due to quality roofing membranes mechanical anchoring
}

\author{
Jindřich Stodůlka ${ }^{1, *}$, Markéta Bogárová ${ }^{1}$, and Libor Matějka ${ }^{1}$ \\ ${ }^{1}$ VUT FAST, Ústav pozemního stavitelství, Veveří 331/95, 60200 Brno, Czech Republic
}

\begin{abstract}
Anchoring of the layers of flat warm roofs using anchoring elements is nowadays one of the most used technology. This is a frequent technology to repair damaged roofs (total reconstruction, increasing the load on the wind loads, partial repairs etc.). In the European building market there are several suppliers of the enchoring equipment who declare their product's properties in the european technical approvements (ETA). The goal of the article is to demonstrate results of the carried out measurements and their possible impact into practical application of the mechanically anchored systems. This allows reduce the amount of defects to improving flexible watertight membranes. The topic can be considered actual and due to the large number of defects precisely for these types of roofs.
\end{abstract}

\section{Introduction}

Based on the issue of the Directive ETAG 006 [1] are all anchoring elements tested in accordance with unified methodology. The directive ETAG 006 [1] is a document the serves as a basis to test and design the mechanically anchored roofs. Development of anchoring elements with telescopes is combined with growing demands to reduce the impact of spot thermal bridges that arise due to anchoring. [2]

Quality, quality and design of the telescope has a significant influence on the resistance and therefore the durability and longevity of flat roofs. Poorly made plastic telescopes are often the cause of the crash roofs. [3]

ETAG 006 [1] defines the roof composition as a system formed with cover waterproofing, thermal insulation, anchoring element and load-bearing layer. Many times is the system defined with the MEFAWAME abbreviation from English "Mechanically fastened waterproofing membranes".

\footnotetext{
* Corresponding author: stodulkaj@study.vutbr.cz
} 


\section{Types of tests and application of their results in the mechanic analysis and review}

The directive recognizes 3 basic types of test, delivering data for the following mechanic analysis of the anchoring (anchoring plan). The basic tests are: large scale (real) test, small scale tests and extracting tests in situ.

The principal of all of the above stated test is to gain information about given system or its component, which are needed for definition of the maximum allowed design loading on one anchoring element - Wadm [N] value.

\subsection{The real scale test}

The real scale test are based on testing of the all roof system - the cover waterproofing, anchoring elements, thermal insulation and load-bearing layer. Full segment of a roof composition is tested in so called pressure chamber that simulates the increasing loading with wind suction. The intensity and increasing of the wind suction are thoroughly described in the directive EAG 006. The result is to define design resistance of one anchoring element Wadm [N] for the concrete system with concrete components from given producers or suppliers of the waterproofing covers and anchoring material.

If there are used system that are tested with the real scale test in the roof, this design of the system is considered the most reliable. According to ČSN EN 1990 [4] the results of the real scale test are the only valid indicators of the suitability of usage of MEFAWAME for its design. However currently the results of the large scale test themselves are possessed only by few of the waterproofing covers. The main portion of the suppliers of the waterproofing covers still declares usual value $400 \mathrm{~N}$ per one anchoring element.

\subsection{Extraction tests in situ}

The extraction test are carried out in cases when the loading capacity of the real loadbearing layer is not sure. The aim of the extraction test is to verify behavior of the concrete anchoring element with the concrete load-bearing layer present in the structure. Output of the tests is to define design loading per one anchoring element but considering the real scale test results.

It is necessary to obtain results from minimum of six test per $5000 \mathrm{~m}^{2}$ of the roof area evenly throughout the roof plane. Minimally $50 \%$ from the total number of the test must be carried out in the area of corners and roof edges.

\subsection{Small scale tests}

The methodology of the MEFAWAME in accordance with directive ETAG 006 allows interchange of some parts or execution of the tested MEFAWAME compared to the real scale test. For such cases is used result of the small scale test which is carried out on each of the roof system component separately. It is possible to swap p.e. anchoring element, cover waterproofing, load-bearing layer etc. The advantage of this types of tests compared to the real scale tests is significantly lower cost.

To allow such interchange in previously tested system (by the real scale test) it is necessary to know the properties of the elements which are interchanged within MEFAWAME. Even here the directive specifies testing of individuals components of MEFAWAME - these tests are considered small scale tests. The output of the small scale 
test is a correlation coefficient $\mathrm{k}[-]$, which enters the calculation of the Wadm value according to relation 1 [1].

$$
W_{-}(a d m, n c)=k \cdot W_{-}(a d m, o c)[\mathrm{N}]
$$

The Wadm,oc $[\mathrm{N}]$ is a design resistance per one anchoring elements of the non-swapped original (from English "Old combination) system MEFAWAME, which is after multiplication with the correlation coefficient $\mathrm{k}[-]$ in accordance with the relation 1 leads to the definition of the design resistance of one anchoring element new (from English. „New Combination“) system MEFAWAME.

In anchoring elements the correlation coefficient is defined as a division of loading capacity of the new and original anchoring element - formula 2 [1].

$$
k(-)=R_{n c}(N) / R_{o c}(N)
$$

The values $R_{n c}[N]$ and $R_{o c}[N]$ are the results of the tension loading capacity of the anchoring elements combined with an exact load-bearing layer. These values are obtained from the results of the small scale tests and the anchoring material suppliers state those in their ETA's. In correlation coefficient which enters the formula for the Wadm,nc calculation there is a restriction for it to be within the interval $0,5-1,0$.

\section{Experimental measurement of the axial tension loading capacity of the anchoring elements.}

Experimental measurement of the axial tension loading capacity was assembled using the „Axial loading test" criteria which is precisely defined in ETAG 006 annex D [1]. From the EN 1990 [4] standard point of view the carried out experimental measurement can be considered a "inspection test to verify identity or quality of given elements" (ČSN EN 1990 - annex D.3 letter. e). As a test samples were chosen anchoring elements with telescopes of length $85-105 \mathrm{~mm}$, that were added with screws $44,8 \times 60$ into trapezoidal metal sheeting.

There were chosen samples from 9 suppliers of the anchoring material from the European building market while every test sample was represented with 10 test bodies. The test bodies were tested in combination with load-bearing layer formed with trapezoidal metal sheeting S280GD of the thickness $0,75 \mathrm{~mm}$. The sheeting S280GD was chosen on purpose because it is mostly used load-bearing layer especially in industrial buildings and shopping center buildings.

\subsection{Testing device and test bodies}

The tearing machine Heckert FT10-1, which was wired to a desktop computer equipped with the CatmanEasy software tool was used for the experimental measurement. During the experiment there were recorded actual forces, displacement and time. The loading speed was set to $10 \mathrm{~mm}$ per minute.

The test bodies were formed with anchoring elements fixed into a metal sheet of $100 \mathrm{x}$ $100 \mathrm{~mm}$. The anchoring was carried out using accumulator screwdriver without predrilling. In the next step the elements were placed into welded elements securing axial transmission of the force into the anchoring element pre-stressed with $5 \mathrm{~N}$ and tested. The graphical scheme of the test is shown in the Fig. 1 and. Fig 2. 


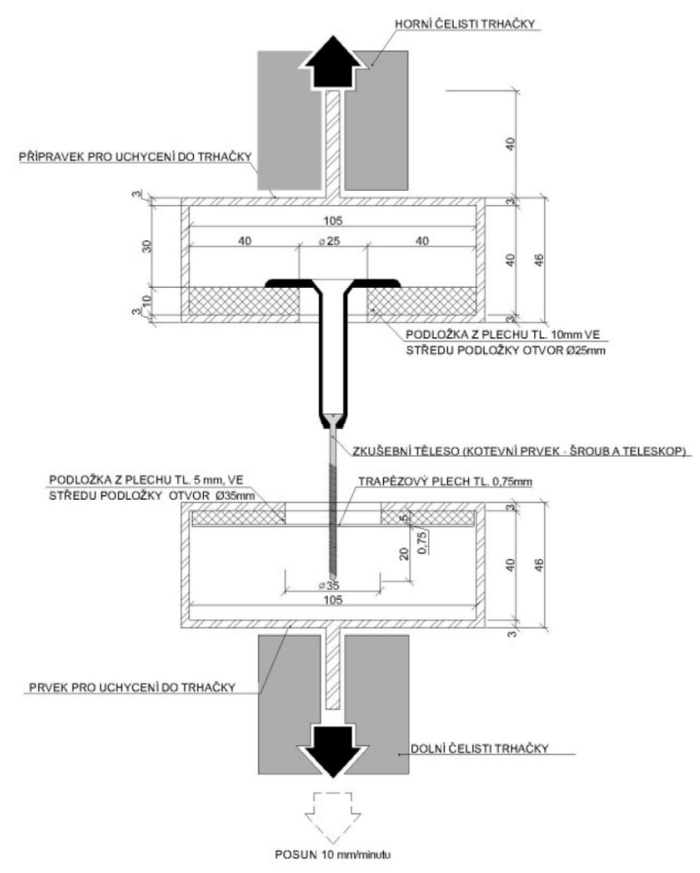

Fig. 1. The scheme of the axial tension loading capacity of anchoring elements test.

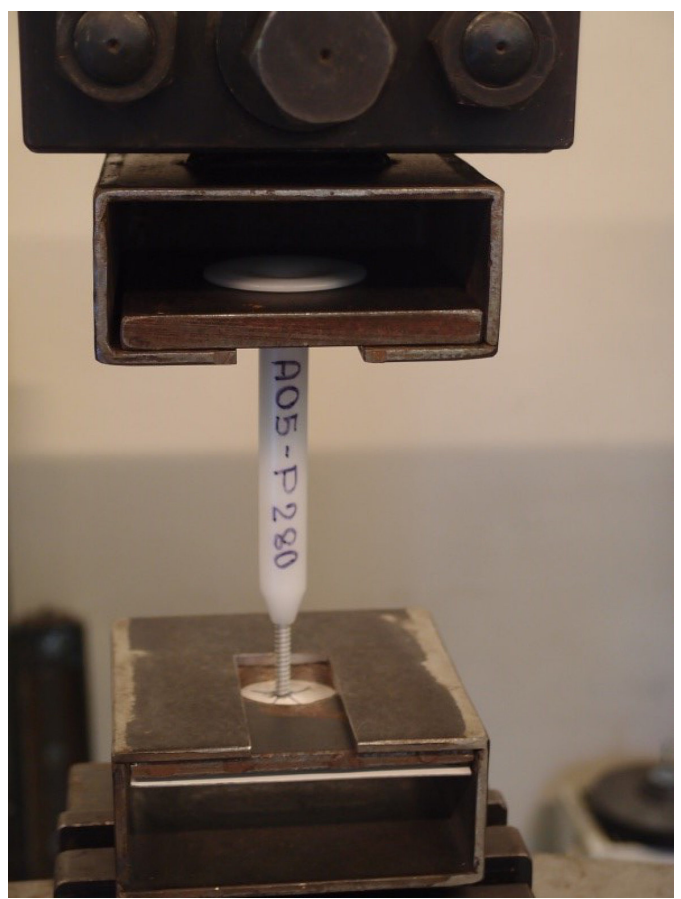

Fig. 2. The test body attached to the testing device.

Pre-stressing to the value of $5 \mathrm{KN}$ was carried out to secure identical initial position in all tested bodies. 


\subsection{Results of experiments, relative and absolute comparion of the middle and characteristic values of loading capacity of anchoring elements}

The input data for the mechanical analysis was the values of maximal forces $\mathrm{F}[\mathrm{N}]$, under which the failure in loading capacity of the test bodies occurred. The characteristic values were defined in accordance with the procedure prescribed in ETAG 006 [1] and ČSN EN 1990 - annex D [4]. The aim was to compare individual test samples with each other and to gain data on the quality of the anchoring elements of the individual suppliers of the anchoring material. Next it was aimed to compare measured values with the values stated in the supplier's ETA's The results of the individual test samples are grouped in the Table 1.

Table 1. Relative comparison of loading capacity of anchoring elements with telescopes.

\begin{tabular}{|c|c|c|c|c|c|c|c|c|c|}
\hline No. & $\mathbf{F}_{\text {average }}$ & $\mathbf{F}_{\mathbf{k}, \mathbf{n}}$ & $\mathbf{F}_{\mathbf{k}, \mathbf{I}}$ & $\mathbf{F}_{\mathbf{K}, \mathbf{E T A}}$ & \multirow{N}{*}{$\mathbf{N o}$} & $\mathbf{F}_{\text {average }}$ & $\mathbf{F}_{\mathbf{k}, \mathbf{n}}$ & $\mathbf{F}_{\mathbf{k}, \mathbf{I}}$ & $\mathbf{F}_{\mathbf{K}, \mathbf{E T A}}$ \\
\hline & {$[\mathbf{N}]$} & {$[\mathbf{N}]$} & {$[\mathbf{N}]$} & {$[\mathbf{N}]$} & & {$[\mathbf{N}]$} & {$[\mathbf{N}]$} & {$[\mathbf{N}]$} & {$[\mathbf{N}]$} \\
\hline A & 1458 & 1396 & 1398 & 1060 & $\mathbf{G}$ & 1361 & 1309 & 1309 & 525 \\
\hline B & 1379 & 1312 & 1313 & 997 & $\mathbf{H}$ & 1442 & 1403 & 1403 & 1060 \\
\hline C & 1422 & 1348 & 1349 & 1680 & $\mathbf{I}$ & 1414 & 1348 & 1349 & 1430 \\
\hline D & 1329 & 1273 & 1274 & 890 & $\mathbf{J}$ & 1417 & 1324 & 1326 & 900 \\
\hline E & 1396 & 1356 & 1356 & 1150 & $\mathbf{K}$ & 1454 & 1376 & 1378 & 1430 \\
\hline F & 1380 & 1295 & 1297 & 970 & & & & & \\
\hline
\end{tabular}

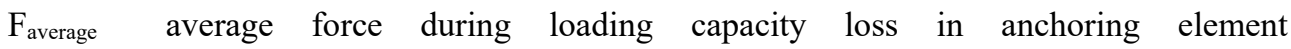
$\mathrm{F}_{\mathrm{k}, \mathrm{n}} \quad$ characteristic loading capacity of anchoring element in normal scatter,

$\mathrm{F}_{\mathrm{k}, 1} \quad$ characteristic loading capacity of anchoring element in log-normal scatter, $\mathrm{F}_{\mathrm{k}, \mathrm{ETA}} \quad$ characteristic loading capacity declared by the manufacturer in ETA.

From the absolute comparison of the characteristic values is visible that in some test samples the measured values does not reach the values stated by the manufacturers in their ETA's. By comparing of the characteristic values in the test sample "I" and "K" it is shown the there is an obvious similarity of the measured middle values of loading capacity $F_{\text {average }}$

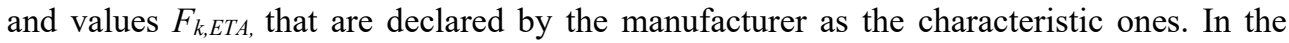
samle "G" the declared values is on contrary significantly lower than the results of the measured values. After precise evaluation of the declared value $F_{k, E T A}$ there was observed similarity with the value $F_{O, R k}[N]$, which can be calculated using theoretical procedure acc to [5].

\section{Conclusion}

The experimental measurement confirmed the doubts of a correctness of a certain data declared in the ETA products. The results show that from the overall number of 11 experimental samples of products the minimum of 3 did not reach the prescribed values.

The misleadingly declared values $\mathrm{F}_{\mathrm{k}, \mathrm{ETA}}$ lead to errors in the correlation coefficients $\mathrm{k}$ (relation 2) and therefore to the wrong definition of the Wadm,nc value. The rest of the sample products showed values in accordance with the stated ones.

The article was developed within the project no. FAST-S-16-3345 "Verifikace chování a rozvoj konstrukcí a konstrukčních prvků na bázi dřeva a kombinovaných konstrukcí ze dřeva a železobetonu" at the Faculty of Civil Engineering VUT in Brno. 


\section{References}

1. ETAG 006. Directive for European Technical Approvals - guideline for European technical approval of systems of mechanically fastened flexible roof waterproofing membranes (European Organisation for Technical Approvals - EOTA, Brussels, 2012)

2. V. Petránek, R. Šubrt, J. Plachý, L. Nevrivová, T. Petř́íček, L. Kalousek, Z. Caha, AMR 732-733, 182-185 (2013)

3. J. Plachý, J. Beránek, Střechy-fasády-izolace, 28-29 (Nakladatelství Mise, Ostrava Vítkovice, 2013)

4. $\check{C} S N$ EN 1990. Eurocode: Eurocode: Basis of structural design (ÚNMZ, Prague, 2011)

5. ČSN EN 1993-1-3. Eurocode 3: Design of steel structures - Part 1-3: General rules Supplementary rules for cold-formed members and sheeting (ÚNMZ, Prague, 2008) 